\title{
Bridging the Gap: The Measure of Urban Resilience
}

\author{
Grazia Brunetta ${ }^{1}\left[\right.$,, Alessandra Faggian ${ }^{2}$ and Ombretta Caldarice ${ }^{1, *(1)}$ \\ 1 Responsible Risk Resilience Centre-R3C, Interuniversity Department of Regional and Urban Studies and \\ Planning, Politecnico di Torino, 10125 Torino, Italy; grazia.brunetta@polito.it \\ 2 Gran Sasso Science Institute, 67100 L'Aquila, Italy; alessandra.faggian@gssi.it \\ * Correspondence: ombretta.caldarice@polito.it; Tel.: +39-011-090-7433
}

Citation: Brunetta, G.; Faggian, A.; Caldarice, O. Bridging the Gap: The Measure of Urban Resilience.

Sustainability 2021, 13, 1113. https:// doi.org/10.3390/su13031113

Received: 14 January 2021

Accepted: 20 January 2021

Published: 21 January 2021

Publisher's Note: MDPI stays neutral with regard to jurisdictional claims in published maps and institutional affiliations.

\section{Understanding Resilience}

The concept of resilience has arisen as a "new way of thinking". It was applied in planning at the end of the last century as a concept that encourages policies to face stress factors and react by renewing and innovating cities. Resilience becomes instrumental in addressing both causes and effects of significant global challenges. As it motivates the transformative potentials of cities, resilience is commonly named "co-evolutionary resilience" [1] or, most recently, "transformative resilience" [2]. Following this more profound meaning, resilience is not only the opposite of vulnerability [3] but also a "broad concept", whose final purpose is to prevent and manage unforeseen events together with the improvement of the environmental and social quality of a territorial system [4]. In a nutshell, this approach characterises resilience as a territorial systems' capacity to respond systemically and dynamically to the present and future shocks related to significant global challenges through non-linear transformation processes. Such processes involve the natural and anthropic characteristics of a territorial system, their performance, quality, and functions [5]. Although the theoretical debate on resilience is deeply investigated, several methodological challenges remain mainly related to the concept's practical sphere. As a matter of fact, resilience is commonly criticised for being too ambiguous and empty meaning. At the same time, turning resilience into practice is not easy to do [6]. We need to measure resilience because its assessment allows consideration of what resilience is practical and what it is possible, and at which point resilience is realistically likely to fail. This will be arguably one of the most impactful global issues for future research on resilience [7].

The Special Issue "Bridging the Gap: The Measure of Urban Resilience" falls under this heading. To the best of our knowledge, it seeks to synthesise the state-of-the-art knowledge of theories and practices on measuring resilience. We were particularly interested in papers that address one or more of the following questions: "What are the theoretical perspectives of measuring urban resilience? How can urban resilience a property to be measured? What are the existing models and methods for measuring urban resilience? What are the main features that a technique for measuring urban resilience needs to guide proper adaptation and territorial governance? What is the role of measuring urban resilience in operationalising cities' ability to adapt, recover and benefit from shocks?"

\section{Measuring Resilience}

For over 40 years, resilience has emerged as a unifying concept in many disciplines linked to sustainability. Efforts to apply resilience within different fields have stimulated interest in measuring resilience, giving rise to various approaches, i.e., qualitative and quantitative methods, participatory assessments, statistical analyses, modelling and metrics [8]. As stated during the 2014 International Food Policy Research Institute (IFPRI) international conference, questions of what to measure, whom to measure, how often to measure, and what methods to use to capture resilience are still being debated. Simultaneously, if no clear guidelines on how to measure resilience reliably exist, decision-makers will not make informed choices about 
how to use it. Resilience will miss the opportunity to be an organising principle, malleable but able to attract different interests and stakeholders together.

Basically, we can identify two main barriers in measuring resilience. The first one is a conceptual barrier, as it is difficult to measure something unless we know precisely what has to be measured. At the same time, the definition of resilience does not facilitate this. Coming to a common and shared understanding of what resilience means is a necessary starting point. As resilience is a continually changing process leading to the idea of dynamic non-equilibrium, the measure of resilience cannot be a single number or a result [9]. The second one is a methodological barrier, as it may not be easy to obtain reliable and meaningful data. As outlined by [10], there is a reliance on using the available data rather than data from a systematic approach. Although several frameworks have been proposed for "capturing resilience" in academic and public discourse, the existing techniques are limited to measuring specific disturbances. Less attention has been directed to consider resilience as a continually changing process. Moreover, the developed resilient metrics are set indicators of what is easy to measure rather than what is important [11].

Based on this introduction, this Special Issue of Sustainability aimed to cover urban resilience measurement by introducing pioneering approaches, discussing experimenting methodologies, and showing possible opportunities for the concept's development. In a very short time, the Special Issue attracted attention from the scientific research community, including 11 published papers, one of which is a review paper focused on comprehensive knowledge regarding multiple methods for measuring resilience. Long Nguyen and Akerar [12] conduct a systematic review of 77 different literature records published from 2000 to 2020, providing an investigation and a more comprehensive picture into the stateof-the-art on modelling, measuring, and visualising community resilience, summarising qualitative, quantitative, and hybrid approaches, and identifying critical points in building community resilience.

Six research papers of this Special Issue assume a methodological perspective that discusses new approaches and required changes to existing methods of measuring resilience. Feldmeyer and colleagues [13] present the result of a project funded by the German Federal Ministry of Education and Research named monitoring of adaptation measures and climate resilience in cities (MONARES). They identify 24 indicators to measure and monitor urban climate resilience for municipalities, assessing the requirements of indicators and implementing a mixed method for adapting global approaches to the local context. The article by Pilone, Demichela and Baldissone [14] presents a semi-quantitative methodology for assessing multiple risks to increase the awareness of municipal technicians. The methodology is based on the assignation of rates to the risks, revealing good feasibility in the results obtained for the interactions, and highlighting some problems neglected in the sectorial risk plans. Brunetta and Salata [15] want to move a step forward from theoretical works on measuring resilience, and particularly they work toward the application of a pioneering empirical methodology to measure and spatially represent the degree of vulnerability (as it is counterpoised to resilience, even if they act simultaneously). The paper by Rota, Bagliani and Feleting [16] proposes a taxonomy of regional resilience using a shift-share analysis based on the region's capacity of improving its employment rate during the pre-crisis period. The paper by Assumma and colleagues [17] investigates the role covered by the system dynamics model (SDM) and Lotka-Volterra models (LV) in supporting the decision-making process in the evaluation of resilience policies. Both the SDM and LV models may be considered reliable supporting tools for policy planning, thanks to their ability to predict possible future behaviours of selected key variables, thus helping stakeholders to identify and prioritise shared strategies for increasing resilience. Lastly, the paper by Mutani, Todeschi and Beltramino [18] aims to cover a research gap of the exiting simulation energy tools and models; namely, to translate the measurement of energy performance from the block of buildings or neighbourhood scale to the city level. The proposed methodology is based on buildings' energy balance, and it is able to carry out simulations at the territorial scale toward energy resilience. 
The remaining four research papers of this Special Issue assume a case-study approach that reads and examines resilience measurement application, thoroughly identifying possible solutions to apply resilience in practice. Urso, Modica and Faggian [19] present Italian inner areas' response to the 2007-2009 Great Recession. The purpose of their paper is to analyse the potential structural change of Italian inner vs. non-inner areas, assessing their adaptive capacity. The authors found that urban poles and inner areas had different capabilities to re-adapt their local industrial compositions in response to the economic crisis with noticeable effects on their future resilience. In the paper by Mohabat Doost and colleagues [20], an empirical application to provide an overall assessment of the solar production capacity in the City of Moncalieri (Turin, Italy) is presented. Results demonstrate that the current minimum energy levels required by law are generally much lower than the effective potential solar energy production that each land use parcel-zone could effectively produce. Abastante and colleagues [21] support that a walkable city means creating a resilient and healthy city. Their paper presents case study research, the Main Campus of the Politecnico di Torino, as a fertile ground for studying a walkability assessment. Lastly, Voghera and Giudice [22] sustain that green infrastructure (GI) is a nature-based solution capable of enhancing the social-ecological quality of a specific territory, both in a sustainable and resilient way. Their paper attempts to fill the gap between evaluation methodology and planning tools compared to GI's indicators in Italy and France.

Author Contributions: Conceptualization: O.C., G.B. and A.F.; writing: O.C. All authors have read and agreed to the published version of the manuscript.

Funding: This research received no external funding.

Conflicts of Interest: The authors declare no conflict of interest.

\section{References}

1. Davoudi, S. Resilience: A bridging concept or a dead end? Plan. Theory Pract. 2012, 13, 299-307. [CrossRef]

2. Giovannini, E.; Benczur, P.; Campolongo, F.; Cariboni, J.; Manca, A. Time for Transformative Resilience: The COVID-19 Emergency; EUR 30179 EN; Publications Office of the European Union: Luxembourg, 2020.

3. White, I.; O'Hare, P. From rhetoric to reality: Which resilience, why resilience, and whose resilience in spatial planning? Environ. Plan. C Gov. Policy 2014, 32, 934-950. [CrossRef]

4. Meerow, S.; Newell, J.P. Urban resilience for whom, what, when, where and why? Urban Geogr. 2016. [CrossRef]

5. Folke, C. Resilience: The emergence of a perspective for social-ecological systems analyses. Glob. Environ. Chang. 2006, $16,253-267$. [CrossRef]

6. Brunetta, G.; Caldarice, O. Spatial Resilience in Planning: Meanings, Challenges, and Perspectives for Urban Transition. In Sustainable Cities and Communities. Encyclopedia of the UN Sustainable Development Goals; Leal Filho, W., Azul, A., Brandli, L., Özuyar, P., Wall., T., Eds.; Springer: Cham, Switzerland, 2020; pp. 1-12.

7. Caldarice, O.; Brunetta, G.; Tollin, N. The Challenge of Urban Resilience: Operationalization. In Urban Resilience for Risk and Adaptation Governance. Theory and Practice; Brunetta, G., Caldarice, O., Tollin, N., Rosas-Casals, M., Moratò, J., Eds.; Springer: Cham, Switzerland, 2019; pp. 1-6.

8. Allen, C.R.; Angeler, D.G.; Cumming, G.S.; Folke, C.; Twidwell, D.; Uden, D.R. Quantifying spatial resilience. J. Appl. Ecol. 2016, 53, 625-635. [CrossRef]

9. Walker, B.H.; Salt, D. Resilience Practice: Building Capacity to Absorb Disturbance and Maintain Function; Island Press: Washington, DC, USA, 2012.

10. Béné, C.; Headey, D.; Haddad, L.; von Grebmer, K. Is resilience a useful concept in the context of food security and nutrition programmes? Some conceptual and practical considerations. Food Secur. 2016, 8, 123-138. [CrossRef]

11. Carpenter, S.R.; Folke, C.; Scheffer, M.; Westley, F. Resilience: Accounting for the non-computable. Ecol. Soc. $2009,14,13$. [CrossRef]

12. Nguyen, H.L.; Akerkar, R. Modelling, Measuring, and Visualising Community Resilience: A Systematic Review. Sustainability 2020, 12, 7896. [CrossRef]

13. Feldmeyer, D.; Wilden, D.; Kind, C.; Kaiser, T.; Goldschmidt, R.; Diller, C.; Birkmann, J. Indicators for Monitoring Urban Climate Change Resilience and Adaptation. Sustainability 2019, 11, 2931. [CrossRef]

14. Pilone, E.; Demichela, M.; Baldissone, G. The Multi-Risk Assessment Approach as a Basis for the Territorial Resilience. Sustainability 2019, 11, 2612. [CrossRef]

15. Brunetta, G.; Salata, S. Mapping Urban Resilience for Spatial Planning-A First Attempt to Measure the Vulnerability of the System. Sustainability 2019, 11, 2331. [CrossRef] 
16. Rota, F.S.; Bagliani, M.; Feletig, P. Breaking the Black-Box of Regional Resilience: A Taxonomy Using a Dynamic Cumulative Shift-Share Occupational Approach. Sustainability 2020, 12, 9070. [CrossRef]

17. Assumma, V.; Bottero, M.; Datola, G.; De Angelis, E.; Monaco, R. Dynamic Models for Exploring the Resilience in Territorial Scenarios. Sustainability 2020, 12, 3. [CrossRef]

18. Mutani, G.; Todeschi, V.; Beltramino, S. Energy Consumption Models at Urban Scale to Measure Energy Resilience. Sustainability 2020, 12, 5678. [CrossRef]

19. Urso, G.; Modica, M.; Faggian, A. Resilience and Sectoral Composition Change of Italian Inner Areas in Response to the Great Recession. Sustainability 2019, 11, 2679. [CrossRef]

20. Mohabat Doost, D.; Buffa, A.; Brunetta, G.; Salata, S.; Mutani, G. Mainstreaming Energetic Resilience by Morphological Assessment in Ordinary Land Use Planning. The Case Study of Moncalieri, Turin (Italy). Sustainability 2020, 12, 4443. [CrossRef]

21. Abastante, F.; Lami, I.M.; La Riccia, L.; Gaballo, M. Supporting Resilient Urban Planning through Walkability Assessment. Sustainability 2020, 12, 8131. [CrossRef]

22. Voghera, A.; Giudice, B. Evaluating and Planning Green Infrastructure: A Strategic Perspective for Sustainability and Resilience. Sustainability 2019, 11, 2726. [CrossRef] 